\title{
O INACREDITÁVEL EMPREGO DE PRODUTOS QUÍMICOS PERIGOSOS NO PASSADO
}

\author{
Luiz Cláudio Ferreira Pimentel, Camille Rodrigues Chaves, Layla Alvim Alves Freire e Júlio Carlos Afonso* \\ Departamento de Química Analítica, Instituto de Química, Universidade Federal do Rio de Janeiro, \\ CP 68563, 21949-900 Rio de Janeiro - RJ, Brasil
}

Recebido em 1/7/05; aceito em 20/9/05; publicado na web em 6/6/06

\begin{abstract}
THE INCREDIBLE USE OF DANGEROUS CHEMICALS IN THE PAST. This work describes an overview of the use of chemicals in several commercial applications along the XXth century. The use of chemicals by men was largely empirical for many centuries, since there was no organized chemical and toxicological knowledge. During the XIXth century the chemical industry gained a crucial role in the development of technology, as evidenced by the extraordinary increase of new products and their incorporation into everyday life. Chemistry was considered a science capable of solving any problem, little regard being paid to the consequences of the widespread use of new chemicals. Efficiency was more important than safety and consumer information. From tragedies and the development of knowledge on toxicology men adopted more careful protocols before a new chemical was proposed for use. Modern life could not exist without the large-scale employment of a variety of chemicals but information on their responsible and conscious use is now essential. Products that were once considered the "last word in technology" have eventually proven dangerous to humans and the environment in the short or long time range. Previous knowledge on the toxicological dangers and the properties of a given substance or product before commercialization is necessary for safe handling.
\end{abstract}

Keywords: dangerous chemicals; safety; commercial chemistry.

\section{INTRODUÇÃO}

O uso de produtos químicos data dos primórdios da civilização. A descoberta do fogo pode fornecer elementos básicos para o desenvolvimento cultural de nossos antepassados. A fabricação de algumas armas e objetos metálicos rudimentares, além de tintas utilizadas na expressão de objetos e animais nas cavernas, demonstram este fato.

Antes mesmo do início da era cristã o homem já dominava as técnicas de cunhagem de moedas, metalurgia, fabricação de espelhos de bronze, assim como a obtenção de mercúrio e amálgamas ${ }^{1}$.

O início do século XVI foi marcado pela publicação de um livro de Hieronymus Brunschwygk (1450-1513) com o nome "Liber de arte distillandi de simplicibus". Este livro teve grande importância porque marcou o início da preocupação do homem em preparar produtos químicos, oriundos de extratos de plantas, que pudessem curar doenças e aliviar a dor. Esta tendência iria se refletir por todo o século XVI e também no XVII, sob o nome de iatroquímica (atualmente, química medicinal), tendo como um dos seus grandes precursores Phillipus Aureolus Paracelsus (1490-1541). Apesar do misticismo que empregava em suas técnicas, induzindo-o a avaliações errôneas, teve sucesso em algumas iniciativas, tais como a utilização de tinturas (extratos alcoólicos), o enxofre (antimicótico) e o ópio (sedativo) ${ }^{1}$.

Após esta fase de utilização mais ou menos empírica de produtos químicos, com o início da I Revolução Industrial (por volta de 1800), houve a mecanização da produção devido ao grande avanço tecnológico decorrente da inserção de máquinas a vapor e de melhorias nos processos produtivos, barateando o preço dos produtos e estimulando o consumo. Esta fase foi fundamental para o surgimento da indústria química moderna ${ }^{2}$.

O século XIX foi marcado pela grande utilização do aço como matéria-prima essencial na produção de máquinas para uma deman-

*e-mail: julio@iq.ufrj.br da industrial que estava em ascensão, além da produção de bens para meios de transporte (locomotivas, navios, etc). A indústria química ganhou projeção como importante setor de ponta no campo fabril. A obtenção de matérias-primas sintéticas a partir dos subprodutos do carvão, nitrogênio e fosfatos ampliou a gama de processos disponíveis e levou à descoberta de novas aplicações para corantes, fertilizantes, explosivos, medicamentos, etc.

Entrava-se no século XX com a visão de universo totalmente transformada pelas possibilidades que se apresentavam pelo avanço tecnológico. A química era tida como uma ciência que transpunha todos os problemas do mundo moderno. Neste ambiente de desenvolvimento industrial, principalmente nas suas últimas décadas, houve um crescimento desenfreado e desmedido na utilização de produtos químicos pelo homem, por conta dos benefícios que se pretendiam obter com os mesmos, acarretando prejuízos tanto ao meio ambiente como à sua própria saúde, e que se faz sentir até os dias atuais ${ }^{3}$.

\section{Periculosidade, insalubridade e as normas trabalhistas associadas ao uso de um produto químico}

No início do século XX, apesar do conhecimento de alguns perigos com relação à manipulação de produtos químicos, em geral pouco ou nenhum cuidado era utilizado. Este fato acarretou inúmeros problemas de saúde e a morte de pessoas que trabalhavam nas indústrias ou mesmo no campo (devido ao emprego de agrotóxicos) pois, além de não utilizarem equipamentos de proteção adequados, não havia nenhuma legislação trabalhista a respeito.

No Brasil, pode-se citar como exemplo o uso agrícola do DDT (diclorodifeniltricloroetano). No passado recomendava-se a sua diluição com água em um recipiente onde se misturava o chamado "caldo" (solução) com o braço e a palma da mão aberta a fim de obter maior homogeneidade. O problema de saúde, devido a esta exposição, somente iria aparecer cerca de 20 a 30 anos depois, devido à sua baixa absorção pela pele. Porém, com a comercialização de novos agrotóxicos, os organofosforados, que possuíam uma dose le- 
tal menor que o DDT, e sem alteração no método de preparo, muitos agricultores morreram antes mesmo de poderem ser socorridos ${ }^{4}$.

Com a criação da Consolidação das Leis do Trabalho - CLT em 1943, por iniciativa do governo brasileiro, foram criadas formas de determinar a periculosidade e a insalubridade de determinados tipos de trabalho associados à exposição e ao uso contínuo de produtos químicos, culminando em maior preocupação com a saúde do trabalhador.

Segundo seu artigo 193: "são consideradas atividades ou operações perigosas, na forma da regulamentação aprovada pelo Ministério do Trabalho, aquelas que, por sua natureza ou métodos de trabalho, impliquem o contato permanente com inflamáveis ou explosivos em condições de risco consumado".

A insalubridade (artigo 189) tem a seguinte apresentação: "Serão consideradas atividades ou operações insalubres aquelas que, por sua natureza, condições ou métodos de trabalho, exponham os empregados a agentes nocivos à saúde, acima dos limites de tolerância fixados em razão da natureza e da intensidade do agente e do tempo de exposição aos seus efeitos".

A partir de 1978, com a portaria $n^{\circ} 3214$, foram aprovadas as chamadas normas regulamentadoras (NR) com base na CLT, gerando importante crescimento com relação à segurança e à saúde dos trabalhadores. Pode-se destacar com relação ao uso de produtos perigosos as seguintes normas:

NR-06 - Trata dos EPI’s (Equipamentos de Proteção Individual) definindo como obrigação da empresa o seu fornecimento gratuito aos seus empregados;

NR-15 - Trata de atividades e operações insalubres, definindo limites de tolerância (o máximo ou mínimo de exposição sem risco à saúde do trabalhador) para a manipulação de produtos químicos e estipulando uma faixa de 10 a 40\% do salário mínimo local adicional ao salário;

NR-16 - Trata das atividades e operações perigosas, onde se empregam produtos explosivos sujeitos a degradação química ou autocatalítica e sujeitas à ação de agentes exteriores, estipulando como adicional $30 \%$ do salário base.

\section{Toxicologia}

A toxicologia é a ciência que estuda as substâncias tóxicas ou venenosas e sua capacidade de interferir em organismos vivos, sejam eles plantas ou animais, assim como estudar antídotos e métodos de análise. Antes de se tornar uma ciência, a toxicologia tinha essencialmente uma natureza empírica, pois servia apenas para saber o que era benéfico ou não à saúde 5 .

Sua origem como ciência data do início do século XIX graças a um espanhol chamado M. J. B. Orfila (1787-1853). Em 1815, ele publicou um livro sobre substâncias tóxicas em organismos, chamado "Traité des Poisons Tirés des Règnes Minéral, Végétal et Animal, ou, Toxicologie Générale Considérée sous les Rapports de la Phisiologie, de la

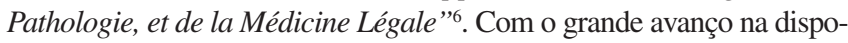
nibilidade de produtos químicos por meio da industrialização, a partir do final do século XIX, a toxicologia ganhou importância com o objetivo de proteger uma sociedade que se industrializava. Atualmente, de acordo com dados da ACS (American Chemical Society), existem no mundo mais de 11 milhões de substâncias químicas, sendo que cerca de 80 mil estão entre as de uso mais comum, seja na indústria alimentícia, farmacêutica ou de uso doméstico ${ }^{7,8}$. Este fato mostra a enorme possibilidade de exposição do homem a produtos químicos, seja em casa, no lazer ou mesmo no ambiente de trabalho, ainda mais quando se sabe que não há substância química desprovida de toxicidade ${ }^{8}$.

Para que uma substância química se torne danosa à saúde, deve haver contato com o organismo. As formas de absorção são basica- mente três: digestiva, respiratória e cutânea. A absorção implica que a substância química atravesse as membranas biológicas, ou seja, alcance a corrente sanguínea, onde é então distribuída por todo organismo e biotransformada em determinados órgãos, produzindo efeitos tóxicos, em alguns casos cumulativos, e posteriormente sendo eliminada do organismo. Este fator de absorção está ligado principalmente às propriedades físicas e químicas da substância ${ }^{9}$. Alguns metais, ou seus sais, ligam-se de forma estável a proteínas e tecidos biológicos, causando um aumento bioacumulativo e uma inibição da excreção. Pode-se citar como exemplos, os metais como chumbo e rádio (radioativo) que se acumulam no tecido ósseo; cádmio e mercúrio que se acumulam nos rins ${ }^{5}$.

Na ingestão de uma substância, esta pode ser absorvida em qualquer parte do trato gastrointestinal, principalmente no intestino delgado passando ao sistema circulatório e chegando diretamente ao fígado. A inalação é a via mais rápida pela qual uma substância química ingressa no organismo. A via cutânea é outra via de ingresso importante. A espessura da pele nas distintas regiões do organismo influi na absorção. Assim, na região do abdômen, por ex., onde a pele é mais fina, a absorção é mais rápida que em outras onde a pele é mais grossa, como a planta dos pés ou a palma das mãos. Quando uma área grande de pele estiver em contato com uma substância química, a quantidade absorvida será maior que aquela de uma superfície pequena ${ }^{7,9}$.

O tempo de contato também é importante, sendo maior a absorção quanto maior for o tempo de contato. Uma forma de classificação deste contato com relação à toxicidade, realizadas com animais, é o chamado tempo de resposta onde se tem"

Toxicidade aguda - exposição única ou múltipla a uma substância por qualquer via em um curto período, inferior a um dia. Observam-se problemas rapidamente;

Toxicidade subcrônica - exposições diárias repetidas a uma substância, por qualquer via. Aparecem problemas em aproximadamente $10 \%$ do tempo de vida de exposição ou alguns meses;

Toxicidade crônica - exposições por um período longo de tempo, geralmente durante toda a vida do animal ou cerca de $80 \%$ do tempo de vida.

Um parâmetro importante em toxicologia é a chamada dose letal $50\left(\mathrm{DL}_{50}\right)$, definida como a quantidade de uma substância química que, quando administrada em uma única dose por via oral, expressa em massa da substância por massa de animal (os mais usados são ratos, camundongos, coelhos, peixes e diversas espécies de macacos), produz a morte de $50 \%$ dos mesmos dentro de um período de observação de 14 dias ${ }^{10}$ (Tabela 1). Conforme os níveis diferenciados de $\mathrm{DL}_{50}$, as substâncias químicas recebem diferentes classificações quanto ao seu nível de toxicidade ${ }^{6}$.

Apesar do avanço na área toxicológica, principalmente com relação às substâncias químicas, ainda hoje pouco se sabe a respeito da toxicidade de muitos produtos químicos comercializados (somente se têm fichas de dados de segurança e toxicidade para cerca de $6 \%$

Tabela 1. $\mathrm{DL}_{50}$ aguda e escala de toxicidade para algumas substâncias químicas ${ }^{6,7}$

\begin{tabular}{lcc}
\hline $\begin{array}{l}\text { Substância } \\
\text { química }\end{array}$ & $\begin{array}{l}\mathrm{DL}_{50} \text { rato macho via oral; } \\
\mathrm{mg} \mathrm{kg}^{-1} \text { de peso corporal }\end{array}$ & Escala de toxicidade \\
\hline Etanol & 7000 & Praticamente atóxico \\
Cloreto de sódio & 3000 & Praticamente atóxico \\
Sulfato de cobre & 1500 & Levemente tóxico \\
DDT & 100 & Moderadamente tóxico \\
Nicotina & 60 & Altamente tóxico \\
Tetradotoxina & 0,01 & Extremamente tóxico \\
Dioxina & 0,02 & Extremamente tóxico \\
\hline
\end{tabular}


deles). Isso acarreta como principal conseqüência o fato de muitas substâncias serem liberadas ao consumo sem um devido estudo toxicológico, a fim de detectar características nocivas à saúde humana após uso prolongado ${ }^{11}$.

Este problema poderia ser solucionado através de testes de curta duração e ensaios de exposição prolongada a fim de se verificar as toxicidades aguda e crônica do produto químico, utilizando para tanto estudos epidemiológicos. Um exemplo notável diz respeito à caracterização das substâncias quanto ao seu potencial carcinogênico. Os testes de curta duração (os mais utilizados são os testes in vitro com a bactéria salmonela) fornecem resultados rápidos e sensíveis, além da vantagem de terem um baixo custo. A eficácia deste teste está estimada em $90 \%$ de acerto para a determinação de um produto como carcinogênico ou não ${ }^{11}$. Já os testes de toxicidade crônica visam estipular limites de segurança da manipulação de determinado produto. Este limite é determinado através da exposição de animais de laboratório a diversas doses e os resultados são extrapolados para seu uso pelo homem. No entanto, a grande limitação dos testes epidemiológicos está no fato do longo período de latência para o desenvolvimento de cânceres e doenças crônicas ao homem, devido ao uso de determinado produto químico. Além disso, atualmente, ocorrem problemas de ordem ética relativos ao uso de cobaias em experimentos (incluindo práticas de vivissecção), assunto de grande discussão no meio científico.

\section{Segurança na identificação de produtos químicos em rótulos no início do século $\mathrm{XX}$}

Em meados do século XIX já havia um consenso entre fabricantes de que os produtos químicos deveriam apresentar em seus rótulos informações ao consumidor a respeito de segurança, como se conhece atualmente, tais como a toxicidade, se é inflamável ou não e até mesmo os cuidados na sua manipulação ${ }^{12,13}$. A partir de 1920 surgiu o símbolo de veneno, utilizado até hoje, que é uma caveira branca sobre um fundo preto.

Este fato deveu-se à crescente utilização dos produtos químicos por profissionais que, muitas vezes, desconheciam o risco a que estavam se expondo ${ }^{14}$. Apesar dessa preocupação aparente, os produtos que eram comercializados e de uso mais popular, como alguns remédios e alguns produtos de uso pessoal e doméstico, não traziam as informações essenciais sobre o risco de sua utilização, tornandoos um perigo para pessoas não acostumadas aos mesmos.

\section{A DESCRIÇÃO DO EMPREGO DE PRODUTOS QUIMICOS NO PASSADO}

Através da pesquisa em catálogos e livros compreendendo o período $1890-1950^{5,15-33}$, listam-se nas Tabelas 2 a 6 alguns exemplos inusitados (e mesmo absurdos para o nível de conhecimento atual)

Tabela 2. Produtos de uso industrial

\begin{tabular}{ll}
\hline Composto & Aplicações de outrora \\
\hline $\mathrm{Sr}(\mathrm{OH})_{2}$ (Hidróxido de estrôncio) & $\begin{array}{l}\text { Utilizado para extrair o açúcar do melaço de } \\
\text { beterraba através dos "açucaratos" de estrôncio }\end{array}$
\end{tabular}

Efeitos colaterais/tóxicos hoje conhecidos

Perigoso se ingerido ou inalado. Causa irritação na pele, nos olhos e no trato respiratório. Forma soluções fortemente alcalinas. Causa queimaduras na área de contato $^{16}$. Poluente de sistemas hídricos: uma concentração de $1500 \mathrm{mg} \mathrm{L}^{-1}$ mata salmões em até 2 semanas ${ }^{18}$

$\mathrm{Ba}(\mathrm{OH})_{2}$ (Hidróxido de bário)

$\mathrm{Na}_{2} \mathrm{~S}$ (Sulfeto de sódio)

$\mathrm{NH}_{3}$ (Amônia)

$\mathrm{K}_{2} \mathrm{Cr}_{2} \mathrm{O}_{7} / \mathrm{Na}_{2} \mathrm{Cr}_{2} \mathrm{O}_{7}$

(Dicromato de potássio e de sódio)
Assim como o hidróxido de estrôncio, era também utilizado para extrair o açúcar do melaço de beterraba, porém caiu em desuso, principalmente na Itália, devido ao alto custo ${ }^{15}$

Utilizado como agente mordente para tingimento de tecidos. Concentração típica: solução a $20 \%{ }^{17}$

Utilizada pura como desengordurante das lãs e meio refrigerante ${ }^{19}$

Sua principal utilização industrial era como agente mordente para tingimento de tecidos ${ }^{17} \mathrm{e}$ na galvanoplastia (cromagem). As soluções de $\mathrm{Cr}$ (VI) têm concentração típica de $300 \mathrm{~g} \mathrm{~L}^{-1} \mathrm{e}$ as de $\mathrm{Cr}(\mathrm{III}), 30 \mathrm{~g} \mathrm{~L}^{-1}$
Pode ser fatal se ingerido. Causa irritação na pele, nos olhos e no trato respiratório. Afeta os músculos, incluindo o coração e o sistema nervoso central ${ }^{16}$, podendo levar ao colapso e à morte. Poluente de águas. $\mathrm{DL}_{50}=550 \mathrm{mg} \mathrm{kg}^{-1}$ (rato, via oral) ${ }^{18}$

Em contato com ácidos liberta gás tóxico $\left(\mathrm{H}_{2} \mathrm{~S}\right)$. Provoca queimaduras e é altamente corrosivo. Muito tóxico para organismos aquáticos ${ }^{18}$. $\mathrm{DL}_{50}=254 \mathrm{mg} \mathrm{kg}^{-1}$ (rato, via oral) e $<340 \mathrm{mg} \mathrm{kg}^{-1}$ (coelhos, via cutânea) ${ }^{18}$

Os sintomas de exposição prolongada são: irritação dos olhos, nariz e garganta; dispinéia, bronco espasmo e dor no peito, além de queimaduras na pele e vesicularização ${ }^{20}$. Altamente tóxica para organismos aquáticos. Lenta degradação no meio ambiente ${ }^{18}$. Na área de refrigeração, foi substituído pelos "freons" (cloro-fluoro-carbonos, CFC's). $\mathrm{DL}_{50}=350 \mathrm{mg} \mathrm{kg}^{-1}$ (rato, via oral, solução a $29 \%)^{18}$

Podem causar câncer por inalação, alterações genéticas hereditárias e sensibilização em contato com a pele. Muito tóxicos também por inalação e ingestão. Irritantes para as vias respiratórias e pele. Risco de graves lesões oculares. Muito tóxicos para organismos aquáticos. É necessária instrução prévia para sua utilização ${ }^{18}$. Ainda são utilizados na galvanoplastia, mas verifica-se a substituição de banhos de $\mathrm{Cr}$ (VI) por $\mathrm{Cr}(\mathrm{III}) . \mathrm{DL}_{50}=25 \mathrm{mg} \mathrm{kg}^{-1}$ (rato, via oral) ${ }^{18}$ 
Tabela 3. Produtos de uso farmacêutico

\begin{tabular}{ll}
\hline Composto & Aplicações de outrora \\
\hline $\mathrm{As}_{2} \mathrm{O}_{3}$ (Anidrido arsenioso) & Aumentava a capacidade física do homem, \\
& porém se devia manter doses regulares da \\
& substância. Uma outra aplicação interna era \\
& purificar o sangue. Caso houvesse intoxicação \\
& por dose excessiva, utilizava-se como antídoto \\
& hidróxido férrico recém preparado \\
&
\end{tabular}

$\mathrm{NH}_{3}$ (Amônia)

$\mathrm{AgNO}_{3}$ (Nitrato de prata)

$\mathrm{Hg}_{2} \mathrm{Cl}_{2}$ (Cloreto mercuroso)

$\mathrm{OsO}_{4} / \mathrm{K}_{2} \mathrm{OsO}_{5}$ (Tetróxido de ósmio/osmato de potássio)

$\mathrm{C}_{10} \mathrm{H}_{8}$ (Naftaleno)

NaSCN (Tiocianato de sódio)

$\mathrm{V}_{2} \mathrm{O}_{5}$ (Pentóxido de vanádio)

$\mathrm{UO}_{2}\left(\mathrm{NO}_{3}\right)_{2} \cdot 6 \mathrm{H}_{2} \mathrm{O}$ (Nitrato de uranila)

$\mathrm{CHCl}_{3}$ (Clorofórmio)
Uso interno no combate à embriaguez, sendo ingerido dissolvido em água (solução a 0,1$0,5 \%)$ e em pequenas doses ${ }^{19}$

Uso interno (solução a 0,2-1,0\% ou ingestão de comprimido contendo $10 \mathrm{mg}$ ) no tratamento de doenças do sistema nervoso e epilepsia. Era também conhecido como "Cáustico Lunar", nome sugerido por Paracelsus, devido à semelhança entre a prata e a lua

Uso externo no tratamento de parasitas e no combate à sífilis, sendo administrado como ungüento, onde triturava-se o sal $(1 \% \mathrm{~m} / \mathrm{m}) \mathrm{com}$ graxa. No comércio, era vendido na forma coloidal sob nome de d'hyrgol ${ }^{24}$

Uso interno no tratamento de ataques de epilepsia, sendo aplicado através de injeção subcutânea de solução a $1 \%{ }^{24}$

Uso interno no tratamento de diarréia, febre tifóide e tuberculose $\mathrm{e}^{25}$ e também era ingrediente da popular "naftalina" (anti-fungo). Cada dose continha $0,1-0,6 \mathrm{mg}$ do composto

Uso interno no tratamento de hipertensão arterial (injeção endovenosa de solução contendo 0,03-0,3 g do sal), porém era contra-indicado em casos de nefrite e insuficiência renal ${ }^{25}$

Uso interno no tratamento de anemias para Cada dose continha $0,25 \mathrm{mg}$ do óxido. Era considerado tônico e, também, utilizado em casos de reumatismo, tuberculose e gota ${ }^{25}$

Uso interno no tratamento de diabetes e também tinha aplicações como antisséptico (1:200) em solução aquosa. Na forma de spray era utilizado no tratamento de doenças da garganta ${ }^{25}$

Uso interno (dose de $1 \mathrm{~mL}$ ) no tratamento de cólicas, diarréia, flatulência, epilepsia, tétano, tosse espasmódica e asma; seu uso externo era puro no tratamento de reumatismo e artrite ${ }^{25}$. No século XIX e no início do XX, foi usado como anestésico suprir a deficiência de oxigênio da hemoglobina.
Efeitos colaterais/tóxicos hoje conhecidos

Perigosamente venenoso. $\mathrm{O}$ arsênio e seus compostos são muito tóxicos por inalação ou ingestão. A exposição prolongada tem sido associada a riscos de câncer de pulmão, pele, fígado, rins e bexiga ${ }^{20}$. $\mathrm{DL}_{50}=$ $14,6 \mathrm{mg} \mathrm{kg}^{-1}$ (rato, via oral) ${ }^{18}$

Os sintomas de exposição prolongada são irritação dos olhos, nariz e garganta; dispinéia, bronco espasmo e dor no peito, além de queimaduras na pele e vesicularização ${ }^{20} . \mathrm{DL}_{50}=350 \mathrm{mg} \mathrm{kg}^{-1}$ (rato, via oral, solução a $29 \%)^{18}$

Cáustico e irritante para pele e mucosas. Sua ingestão pode causar gastroenterite séria, que pode evoluir para óbito $^{23}$. Tóxico para organismos aquáticos. Uso externo na remoção de verrugas (bastão de $\mathrm{AgNO}_{3}$ ). $\mathrm{DL}_{50}=$ $1173 \mathrm{mg} \mathrm{kg}^{-1}$ (rato, via oral) ${ }^{18}$

Tóxico por inalação. Pode sensibilizar a pele. Perigo de efeitos cumulativos. Muito tóxico para organismos aquáticos ${ }^{18,20,23}$. O sistema neurológico é afetado irreversivelmente. $\mathrm{DL}_{50}=210 \mathrm{mg} \mathrm{kg}^{-1}(\text { rato, via oral })^{18}$

Muito tóxico por inalação, em contato com a pele e por ingestão. Provoca queimaduras ${ }^{18,23}$ e cegueira permanente. Afeta a função renal. $\mathrm{DL}_{50}=15 \mathrm{mg} \mathrm{kg}^{-1}$ $(\text { rato, via oral })^{18}$

Nocivo por ingestão. Muito tóxico para organismos aquáticos. Evitar a produção e a inalação de pós ${ }^{19}$. Ainda subsiste seu uso como fungicida. $\mathrm{DL}_{50}=2000$ $\mathrm{mg} \mathrm{kg}^{-1}$ (rato, via oral) $)^{18}$

Causa irritação na pele, nos olhos e no sistema respiratório. Pode afetar coração, sangue, tireóide e sistema nervoso central ${ }^{16}$. Libera gases tóxicos em contato com ácidos ${ }^{18}$. $\mathrm{DL}_{50}=764 \mathrm{mg} \mathrm{kg}^{-1}$ (rato, via oral) ${ }^{18}$

Perigoso por ingestão ou inalação. Irritante para o sistema respiratório. Risco possível de aborto ${ }^{18}$. Agente oxidante sobre estruturas biológicas. Poluente hídrico. $\mathrm{DL}_{50}=400-500 \mathrm{mg} \mathrm{kg}^{-1}$ (rato, via oral) ${ }^{18}$

Sais de urânio apresentam alta toxicidade do ponto de vista químico e radiológico. Favorecem os cânceres e afetam os rins ${ }^{26} . \mathrm{DL}_{50}=20-25 \mathrm{mg} \mathrm{kg}^{-1}$ (rato, via oral); $0,1 \mathrm{mg} \mathrm{kg}^{-1}$ (coelho, via oral) ${ }^{18}$

Nocivo por ingestão. Irritante para a pele. Possibilidade de efeitos cancerígenos. Risco de efeitos graves para a saúde em caso de exposição prolongada por inalação e ingestão ${ }^{18}$. Poluente hídrico. $\mathrm{DL}_{50}=908 \mathrm{mg} \mathrm{kg}^{-1}$ (rato, via oral $)^{18}$ 
Tabela 3. continuação

\begin{tabular}{ll}
\hline Composto & Aplicações de outrora \\
\hline Petróleo & Uso interno como expectorante e vermífugo; uso \\
& externo como antisséptico e para tratamento de \\
& doenças de pele. Em cada dose o paciente \\
& tomava $1-2 \mathrm{~mL}$ do produto
\end{tabular}

$\mathrm{CdSO}_{4}$ (Sulfato de cádmio)

HCl (Ácido clorídrico)

$\mathrm{C}_{6} \mathrm{H}_{6}$ (Benzeno)

$\mathrm{C}_{5} \mathrm{H}_{5} \mathrm{~N}$ (Piridina)

$\mathrm{KBr} / \mathrm{NaBr} / \mathrm{NH}_{4} \mathrm{Br}$ (Brometos de potássio, de sódio e de amônio)

$\mathrm{CCl}_{4}$ (Tetracloreto de carbono)

Sb (Antimônio)

$\mathrm{C}_{6} \mathrm{H}_{5} \mathrm{OH}($ Fenol)
Era empregado com uso interno, a fim de aumentar a ação digestiva do estômago. Era administrado em forma de solução $(0,2: 100)^{28}$

Usado no tratamento da leucemia através de sua inalação puro, e como uso externo no tratamento de pediculose e seborréia ${ }^{25}$. Hortelã era às vezes adicionada para "aromatizar" a inalação. A dose máxima era de $3 \mathrm{~mL}$ por aplicação.

Tratamento de asma e bronquite crônica. O paciente era deixado em uma sala fechada onde inalava o produto puro por cerca de 30 min por até 3 vezes ao $\operatorname{dia}^{25}$. Era costume misturá-la com mentol ou eucalipto

Uso interno atuando sobre o cérebro, diminuindo a excitabilidade da substância cortical. Poderoso sedativo nervino, remédio contra epilepsia, insônia, convulsões e irritabilidade nervosa $^{29}$. Empregava-se uma mistura sólida dos três sais em proporções mássicas iguais ${ }^{29}$

Utilizado como vermífugo. A dose era de 2,5 $\mathrm{mL}$ para adultos ${ }^{25}$

Era empregado puro na forma de pílulas chamadas "perpétuas", que eram ingeridas para efeitos purgativos e depois recolhidas quase intactas para servirem a novas aplicações ${ }^{30}$

No tratamento da diarréia, fermentação gástrica (spray a $1 \%$ ) e tétano, sendo este último na forma injetável (solução endovenosa a 1\%). Seu uso externo era no tratamento de hemorróida e como desinfetante (solução a 0,5-5 \%) ${ }^{25}$
Efeitos colaterais/tóxicos hoje conhecidos

A toxicidade depende da composição do óleo. Alguns óleos crus e frações provocam tumores malignos e benignos em ratos, após aplicação sobre a pele ${ }^{27}$. A $\mathrm{DL}_{50}$ depende do óleo considerado

Cádmio além de ser venenoso, afetando muitas enzimas, é cumulativo no organismo, possuindo meiavida biológica de 20 a 30 anos. É acumulado em maior quantidade no fígado e nos rins ${ }^{5}$. Agente cancerígeno ao homem e poluente hídrico. $\mathrm{DL}_{50}=280 \mathrm{mg} \mathrm{kg}^{-1}$ (rato, via oral $)^{18}$

Sua ingestão, inalação de seus fumos ou contato com a pele pode causar queimaduras. É um forte agente corrosivo. Os sintomas, após ingestão ou contato com a pele, incluem dor imediata e ulceração de todas as membranas e tecidos que entrarem em contato com o ácido. A ingestão em excesso era associada a vômitos, náuseas e corrosão estomacal que pode, em poucas horas ou dias, causar sua perfuração e morte ${ }^{20}$. Poluente hídrico. A inalação durante $1 \mathrm{~h}$ de $\mathrm{HCl}$ numa concentração de 3124 ppm mata 50\% dos ratos submetidos a esse teste ${ }^{18}$

Pode causar câncer. Facilmente inflamável. Risco de efeitos graves para a saúde em caso de exposição prolongada por inalação, contato com a pele e ingestão. Leva à anemia aplásica da medúla óssea ${ }^{18}$. $\mathrm{DL}_{50}=930$ $\mathrm{mg} \mathrm{kg}^{-1}$ (rato, via oral) $)^{18}$

Facilmente inflamável. Nocivo por inalação, em contato com a pele e por ingestão ${ }^{18}$. Leva a disfunções sexuais nos indivíduos machos. $\mathrm{DL}_{50}=890 \mathrm{mg} \mathrm{kg}^{-1}$ (rato, via oral); $1121 \mathrm{mg} \mathrm{kg}^{-1}$ (coelho, via cutânea) ${ }^{18}$

A toxicidade é parecida para os três sais. A ingestão afeta o sistema nervoso central, cérebro e olhos. Podem causar irritações na pele e no trato respiratório ${ }^{16}$. $\mathrm{DL}_{50}$ (rato, via oral) $^{18}$ : $\mathrm{NH}_{4} \mathrm{Br}, 2714 \mathrm{mg} \mathrm{kg}^{-1} ; \mathrm{KBr}, 3070 \mathrm{mg}$ $\mathrm{kg}^{-1}$; $\mathrm{NaBr}, 3500 \mathrm{mg} \mathrm{kg}^{-1}$

Tóxico por inalação, em contato com a pele e por ingestão. Possibilidade de efeitos cancerígenos. Risco de efeitos graves para a saúde em caso de exposição prolongada por inalação ${ }^{18,23}$. Produção banida no território nacional. $\mathrm{DL}_{50}=1770 \mathrm{mg} \mathrm{kg}^{-1}$ (rato, via oral); $5070 \mathrm{mg} \mathrm{kg}^{-1}$ (rato, via cutânea) ${ }^{18}$

Antimônio e seus compostos causam dermatites, queratites, conjuntivites e ulcerações septo-nasais pelo contato com fumos e poeira ${ }^{20}$. $\mathrm{DL}_{50}=7000 \mathrm{mg} \mathrm{kg} \mathrm{kg}^{-1}$ $(\text { rato, via oral })^{18}$

Tóxico em contato com a pele e por ingestão. Provoca queimaduras ${ }^{18,23}$ que dificilmente cicatrizam. Poluente hídrico. Usado pelos nazistas como injeção letal em campos de concentração. $\mathrm{DL}_{50}=317 \mathrm{mg} \mathrm{kg}^{-1}$ (rato, via oral); $669 \mathrm{mg} \mathrm{kg}^{-1}$ (rato, via cutânea) ${ }^{18}$ 
Tabela 4. Produtos de uso agrícola

\begin{tabular}{|c|c|c|}
\hline Composto & Aplicações de outrora & Efeitos colaterais/tóxicos hoje conhecidos \\
\hline $\mathrm{CS}_{2}$ (Dissulfeto de carbono) & $\begin{array}{l}\text { Defensivo agrícola contra parasitas e outras } \\
\text { pragas }^{25} \text {, particularmente as das parreiras. } \\
\text { Empregado puro }\end{array}$ & 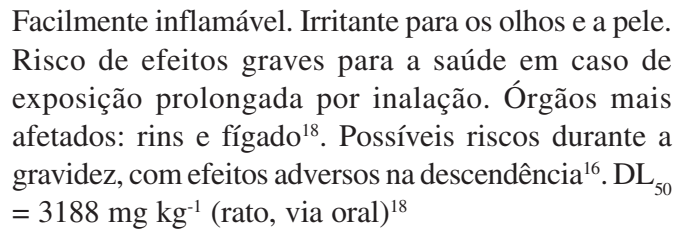 \\
\hline
\end{tabular}

$\mathrm{HgCl}_{2}$ (Cloreto mercúrico)

$\mathrm{CuSO}_{4}$ (Sulfato cúprico)

$\mathrm{Cu}\left(\mathrm{C}_{2} \mathrm{H}_{3} \mathrm{O}_{2}\right)_{2} 3 \mathrm{Cu}\left(\mathrm{AsO}_{2}\right)_{2}$ (Acetoarsenito de cobre) (Verde de Paris)

$\mathrm{Ca}_{3}\left(\mathrm{AsO}_{4}\right)_{2}$ (Arseniato de cálcio)
Aplicado sob forma de solução aquosa (1:10005000) em sementes de batata para tratamento de pragas $^{25}$

Tipicamente, misturava-se uma parte do sal com uma parte de leite de lima (uma mistura cáustica) e 100 partes de água; obtinha-se hidróxido cúprico $\left(\mathrm{Cu}(\mathrm{OH})_{2}\right)$ na forma sólida e uma fase aquosa. A esta solução dava-se o nome de mistura Bordeaux e era aplicada em videiras e outras plantas para prevenção do crescimento de fungos ${ }^{31}$

Foi introduzido no combate à peste em meados do século XIX, sendo o principal inseticida para combater o escaravelho da batata. Já em 1900 era usado em tão larga escala que levou o governo dos Estados Unidos a estabelecer a primeira legislação no país sobre o uso de insecticidas ${ }^{32}$

Utilizado com a mesma finalidade do Verde de Paris, era um pesticida que compunha de 5 a $45 \% \mathrm{~m} / \mathrm{m}$ do produto comercial ${ }^{33}$
Muito tóxico por ingestão. Provoca queimaduras. Risco de efeitos graves e permanentes para a saúde em caso de exposição prolongada e contato com a pele. Muito tóxico para organismos aquáticos ${ }^{18}$. $\mathrm{DL}_{50}=1 \mathrm{mg} \mathrm{kg}^{-1}$ (rato, via oral); $40 \mathrm{mg} \mathrm{kg}^{-1}$ (coelho, via cutânea) ${ }^{18}$

Nocivo por ingestão. Irritante para os olhos e a pele. Muito tóxico para organismos aquáticos ${ }^{18,20}$. Uso limitado para tratamento de águas de piscinas. $\mathrm{DL}_{50}=$ $960 \mathrm{mg} \mathrm{kg}^{-1}$ (rato, via oral); $2000 \mathrm{mg} \mathrm{kg}^{-1}$ (rato, via cutânea $)^{18}$

O arsênio e seus compostos são muito tóxicos por inalação ou ingestão. A exposição prolongada tem sido associada a riscos de câncer de pulmão, pele, fígado, rins e bexiga ${ }^{20}$. O composto acabou por ser banido, devido à extrema toxicidade para mamíferos em geral.

Venenoso. O contato direto pode causar irritação na pele. Possui potencial carcinogênico ${ }^{20}$. $\mathrm{DL}_{50}=298 \mathrm{mg}$ $\mathrm{kg}^{-1}$ (rato, via oral) de emprego de substâncias químicas em cinco grandes campos: industrial, farmacêutico, agrícola, doméstico e usos especiais. Dependendo da aplicação de um determinado produto, ele pode figurar em mais de uma categoria. Para cada composto listado, relatam-se suas aplicações no passado e os fatos que explicam a não continuação do seu emprego hoje em dia, face ao estado atual do conhecimento.

Embora esta pesquisa não seja exaustiva, permite distingüir dois grandes campos de aplicação: as áreas farmacêutica e agrícola. Isso reflete bem duas grandes preocupações da humanidade: o combate às doenças e o aumento da oferta de alimentos para uma população sempre crescente, reflexos de um desejo de melhor qualidade de vida. Todavia, mesmo aplicações no cotidiano eram contempladas pelas aplicações dos produtos listados, dentro do mesmo espírito de propiciar conforto e bem-estar às pessoas.

\section{A PREOCUPAÇÃO COM A FINALIDADE IMEDIATA VERSUS OS EFEITOS A LONGO PRAZO}

A química no início do século XX era tida como a solução para os problemas do homem moderno ${ }^{34-36}$. Naquela época já havia uma enorme diversidade de produtos químicos no mercado que se propunham a resolver muitos problemas, não se importando com os meios para isto e as conseqüências decorrentes. Existia mesmo uma preocupação de "uma vez caracterizado um novo composto químico, testes eram feitos para se avaliar seu potencial emprego na medicina, na indústria e no cotidiano com vistas a solucionar os problemas que se apresenta- vam"37. A propaganda, seja em cartazes, anúncios e cartões-postais, tinha papel primordial nesse contexto. De modo geral, os produtos procuravam conquistar o consumidor, especialmente aqueles que nunca tinham tido a possibilidade de desfrutar de um padrão de vida melhor: cura de doenças, controle de pragas (especialmente insetos e ratos), limpeza mais eficiente, menos esforço nos afazeres domésticos... Grosso modo, podem ser distinguidos dois tipos de propaganda: a que valorizava a eficácia frente a uma determinada situação, até mesmo exacerbando suas qualidades, com omissão aos perigos do uso indevido ou de manipulação por pessoas inabilitadas (crianças, principalmente $)^{38,39}$, e a que mostrava as virtudes do produto por meio de uma história fictícia que envolvia e convencia o consumidor a adquirir o mesmo. A sedução era o "segredo" para conquistar novos consumidores, com "boas doses de exagero" 39 prometendo, muitas vezes, confortos e regalias que não se verificavam com o tempo.

A propaganda da Figura 1, de um raticida muito utilizado por décadas ${ }^{40}$, é um exemplo clássico da ênfase sobre a eficiência de um produto (ele continha arsênio em sua formulação).

Existiram também propagandas curiosas de produtos que passavam a idéia de que a Química tinha o poder de criar produtos inesgotáveis, no caso, uma falsa qualidade do produto, como atesta o trecho a seguir ${ }^{38}$ : "os melhores banhos são os de cascatas onde a água nunca se acaba... e os banhos mais deliciosos são tomados com o sabonete Vale Quanto Peza, o sabonete que também nunca se acaba”.

Não obstante a falta de informações sobre os riscos e a segurança quanto ao manuseio para os consumidores, não se pode esquecer 
Tabela 5. Produtos de uso doméstico

\begin{tabular}{|c|c|c|}
\hline Composto & Aplicações de outrora & Efeitos colaterais/tóxicos hoje conhecidos \\
\hline $\mathrm{Hg}_{2} \mathrm{Cl}_{2}$ (Cloreto mercuroso) & $\begin{array}{l}\text { Utilizado como antisséptico e desodorante } \\
\text { (suspensão aquosa a } 0,01-0,1 \%)^{26}\end{array}$ & $\begin{array}{l}\text { Nocivo por ingestão. Irritante para os olhos, as vias } \\
\text { respiratórias e a pele }{ }^{18} . \mathrm{DL}_{50}=210 \mathrm{mg} \mathrm{kg}^{-1} \text { (rato, via oral) }{ }^{18}\end{array}$ \\
\hline $\mathrm{Tl}_{2} \mathrm{SO}_{4}$ (Sulfato de tálio(I)) & $\begin{array}{l}\text { Utilizado na composição de cremes de } \\
\text { depilação para mulheres }{ }^{25} \text {, e também como } \\
\text { raticida }(2 \% \mathrm{~m} / \mathrm{m} \text { da formulação) e formicida } \\
(0,5 \% \mathrm{~m} / \mathrm{m} \text { da formulação })^{26}\end{array}$ & $\begin{array}{l}\text { Sais de tálio são suspeitos de serem cancerígenos. Em } \\
1975 \text {, os EUA proibiram seu uso doméstico, constituindo- } \\
\text { se em crime sua comercialização }{ }^{26} \text {. Causa perda de cabelo, } \\
\text { paralisia, unhas brancas e inflamação do nervo ótico, } \\
\text { coma e morte. Altamente tóxico para organismos aquáticos, } \\
\text { inibe germinações e torna o solo improdutivo }{ }^{18} \text {. } \\
\mathrm{DL}_{50}=10,6 \mathrm{mg} \mathrm{kg}^{-1} \text { (rato, via oral) }\end{array}$ \\
\hline
\end{tabular}

BaS (Sulfeto de bário) Também era utilizado para depilação em concentrações superiores a $5 \% \mathrm{~m} / \mathrm{m}$ nas formulações ${ }^{25}$

$\mathrm{ZrO}_{2}$ (Óxido de zircônio) Assim como o cloreto mercuroso, o óxido de zircônio era encontrado em alguns tipos de desodorantes (suspensão a $0,1-0,5 \%)^{26}$

$\mathrm{SO}_{2}$ (Anidrido sulfuroso) Utilizado como removedor de manchas de vinho em roupas ou tecidos.

Usado em solução aquosa a 5-6\% ${ }^{19}$

$\mathrm{Cl}_{2}$ (Cloro)

Tinha uma denominação de "água de cloro" (solução aquosa a 0,2-0,3\%) e sua principal aplicação estava na higiene ocular e bucal ${ }^{28}$
Veneno $^{23}$. Efeitos similares ao $\mathrm{Ba}(\mathrm{OH})_{2}$, levando até à morte. Em contato com suco gástrico, sangue e linfa libera gás tóxico $\left(\mathrm{H}_{2} \mathrm{~S}\right) . \mathrm{DL}_{50}=375 \mathrm{mg} \mathrm{kg}^{-1}$ (rato, via oral)

Seu uso foi proibido na década de 60 após o aparecimento de granulações nas axilas de consumidores desses produtos ${ }^{26}$. Testes com coelhos não mostraram sinais de irritação ${ }^{18}$. Não se dispõem de dados sobre impactos ambientais ${ }^{18}$

Sintomas de exposição prolongada: irritação aguda de olhos, nariz e garganta; o contato direto com o líquido pode causar congelamento $^{23}$. Uma concentração de 2520 ppm no ar mata $50 \%$ dos ratos em $1 \mathrm{~h}^{18}$

$\mathrm{Cl}_{2}+\mathrm{H}_{2} \mathrm{O} \rightleftharpoons \mathrm{HCl}+\mathrm{HOCl}$

Conforme reação acima, ocorre a produção de ácido hipocloroso, agente oxidante poderoso e corrosivo. Irrita os olhos, a pele e as mucosas 5 .

Por isso, a água sanitária é um caso grave de envenenamento.

$\mathrm{DL}_{50}=<50 \mathrm{mg} \mathrm{kg}^{-1}$ (coelho, via cutânea)

Tabela 6. Outros empregos particulares

\begin{tabular}{|c|c|c|}
\hline Composto & Aplicações de outrora & Efeitos colaterais/tóxicos hoje conhecidos \\
\hline $\mathrm{CCl}_{4}$ (Tetracloreto de carbono) & $\begin{array}{l}\text { Também conhecido como "pireno", o líquido } \\
\text { puro tinha aplicação como extintor de } \\
\text { incêndio }^{26}\end{array}$ & $\begin{array}{l}\text { Tóxico por inalação, em contato com a pele e por ingestão. } \\
\text { Possibilidade de efeitos cancerígenos. Risco de efeitos } \\
\text { graves para a saúde em caso de exposição prolongada por } \\
\text { inalação }{ }^{18,23} \text {. Produção banida em território nacional. } \\
\mathrm{DL}_{50}=1770 \mathrm{mg} \mathrm{kg}^{-1} \text { (rato, via oral); } 5070 \mathrm{mg} \mathrm{kg}^{-1} \\
\text { (rato, via cutânea) })^{18}\end{array}$ \\
\hline HCN (Ácido cianídrico) & $\begin{array}{l}\text { Utilizado puro em navios na forma de spray } \\
\text { para exterminar roedores e matar insetos. } \\
\text { Também usado para matar insetos em árvores. } \\
\text { Era recomendado seu uso somente por pessoas } \\
\text { experientes no seu manuseio }{ }^{25}\end{array}$ & $\begin{array}{l}\text { É uma substância muito tóxica. É um veneno de ação } \\
\text { muito rápida, uma dose de } 60-90 \mathrm{mg} \text { pode matar um ser } \\
\text { humano por absorção oral }{ }^{33} \text { quase instantaneamente. } \\
\mathrm{DL}_{50}=5 \mathrm{mg} \mathrm{kg}^{-1} \text { (rato, via oral, como KCN) }{ }^{18}\end{array}$ \\
\hline $\mathrm{PH}_{3}$ (Fosfina) & $\begin{array}{l}\text { Utilizado puro em bóias flutuadoras de cortiça, } \\
\text { destinadas a serem lançadas à água ao primeiro } \\
\text { grito de alarme }^{19}\end{array}$ & 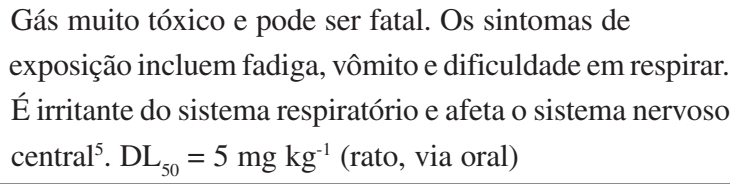 \\
\hline
\end{tabular}




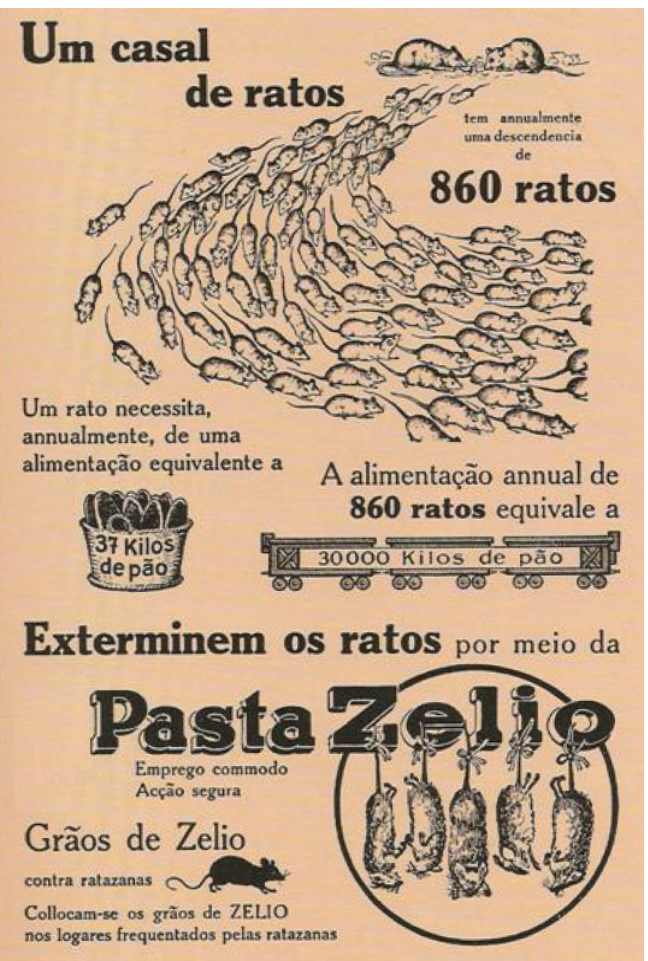

Figura 1. Propaganda da pasta Zélio (raticida). Reproduzido da ref. 40, com permissão de Bayer S. A., copyright ( 1930, Indústrias Chimicas Bayer

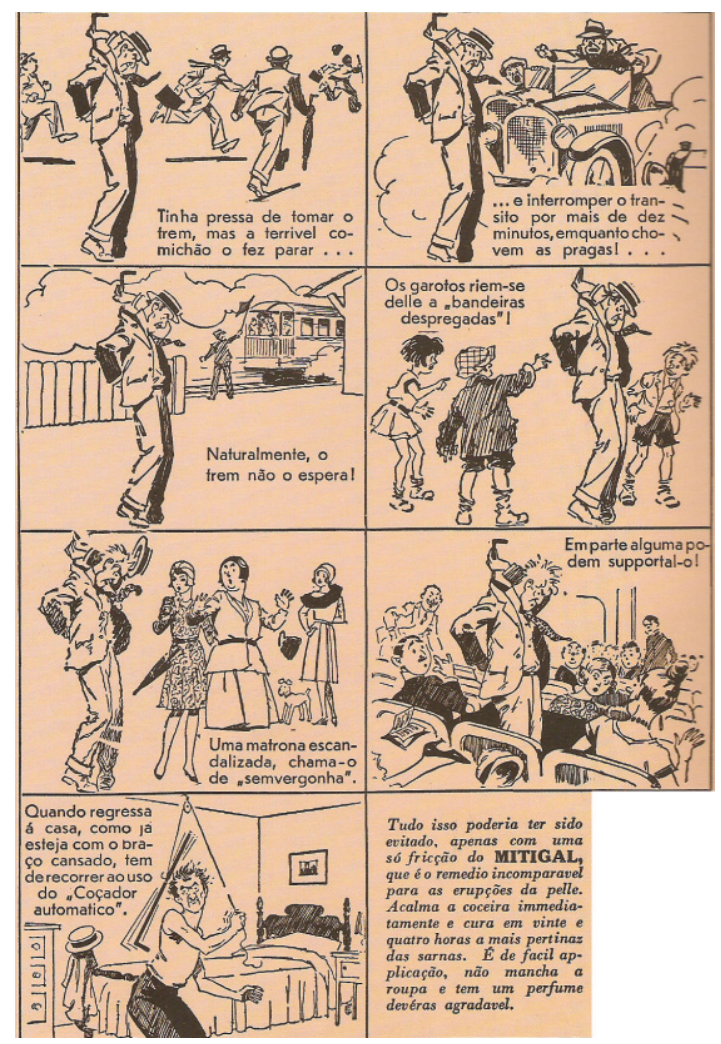

Figura 2. Propaganda de um famoso produto contra coceira, evidenciando a necessidade do mesmo por meio de uma história fantasiosa. Reproduzido da ref. 40, com permissão de Bayer S. A., copyright $\odot$ 1931, Indústrias Chimicas Bayer das propagandas de medicamentos daquela época, que os declaravam extremamente versáteis e multifuncionais, ou seja, poderiam ter diversas aplicações terapêuticas, sendo comum a utilização de histórias fantasiosas mostrando suas diversas qualidades frente a um público que nunca tivera produtos ao seu alcance para as mais diversas necessidades. Como exemplo pode-se citar a propaganda de um famoso produto contra coceira (Figura 2$)^{40}$, onde se destaca o slogan comercial "tem um perfume deveras agradável".

A dosagem também tinha um papel importante no emprego de alguns medicamentos, chegando ao absurdo de se utilizar "doses maciças". Tem-se como exemplo (Figura 3$)^{29}$ o Tribromure de A. Gigon (composição $(\mathrm{m} / \mathrm{m}): 1 / 3$ de brometo de sódio, 1/3 de brometo de potássio e 1/3 de brometo de amônio), em cuja parte da bula aparece em destaque - venda sob prescrição médica ${ }^{29}$.
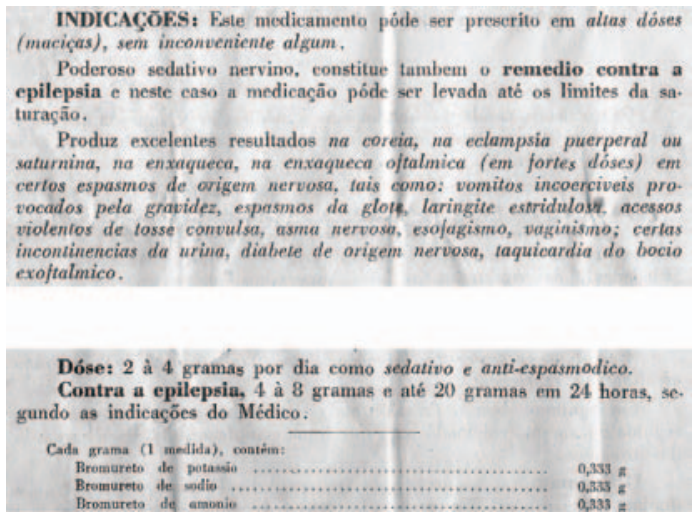

Figura 3. Partes da bula do remédio "Tribromure de A. Gigon" (1941), descrevendo indicações, posologia e composição

A partir dos anos 40, devido a esta multiplicidade funcional dos remédios, começaram a surgir os resultados oriundos desta atitude, com diversas seqüelas relacionadas aos efeitos adversos dos medicamentos, culminando com o episódio mais dramático, nos anos 60 , relativo aos efeitos colaterais do uso indiscriminado da talidomida, especialmente as deformidades em crianças ${ }^{41}$.

Os riscos devido ao uso de produtos químicos não se limitavam à área farmacêutica ou mesmo de produtos para o dia-a-dia. Seu espectro de atuação era muito mais amplo, chegando aos campos agrícolas. Com a crescente expansão demográfica e com o aumento da população mundial houve maior perspectiva de vida devido a melhorias sanitárias. Isso também levou ao aumento da demanda por alimentos e o uso de pesticidas auxiliou, em muito, a um grande aumento da sua produção que, sem eles, não seria possível ${ }^{42}$. O início do emprego de pesticidas tem origem pelo final do século XIX. Nessa época os pesticidas eram na sua maioria sais inorgânicos. Por volta de 1920 começou a utilização de produtos orgânicos que, na realidade, tinham sido antes sintetizados para fins bélicos, devido à sua alta toxicidade em animais e plantas. Após a $2^{\mathrm{a}} \mathrm{Guer}$ ra Mundial sua utilização foi determinante no combate às pragas nas lavouras $^{43}$. Um dos mais famosos pesticidas do século XX foi o diclorodifeniltricloroetano, também conhecido como DDT. Este composto se mostrava eficaz contra uma grande variedade de insetos, levando-o a uma rápida comercialização e a um uso vastíssimo abrangendo, na década de 60, a aplicação para 334 variedades diferentes de produtos agrícolas, só nos Estados Unidos ${ }^{32}$.

Tal fato pode ser comprovado em anúncios e em uma grande campanha realizada em 1947, nos Estados Unidos, para difusão do uso do produto ("DDT is good for me", o DDT é bom para mim). O texto-base desta campanha era" ${ }^{44}$ : "a grande expectativa para o DDT 
tinha sido atingida. Durante o ano de 1946 foram realizados testes científicos exaustivos mostrando que, quando este era usado adequadamente, o DDT era um benfeitor para toda a humanidade".

Assim como os outros produtos químicos milagrosos da época, o DDT foi rapidamente aceito (apelidado como o pesticida "salvavidas": perfeito e eficiente), e aparentemente não era prejudicial à saúde pública. Foram inúmeros os programas de erradicação da malária na maioria dos países desenvolvidos, através do uso do DDT, muitas vezes pulverizado diretamente sobre colheitas, casas, ruas, pessoas, etc. de modo a atacar os mosquitos transmissores da doença $^{32}$. Os efeitos do DDT e de outros pesticidas sobre o meio ambiente foram relatados na obra de Rachel Carson (1907-1964), Primavera Silenciosa ("Silent Spring"), lançada em 1962. De grande impacto na opinião pública norte-americana, suscitou forte reação de repúdio da indústria de pesticidas e pôs em cheque a crença ilimitada na tecnologia como fator de progresso e bem-estar. O governo daquele país acabou por, inicialmente, supervisionar o uso do DDT, até seu banimento anos depois. Esta obra colaborou para mostrar a fragilidade da natureza frente à ação humana e para despertar a necessidade da produção industrial harmonizar-se com o meio ambiente.

\section{A TOXICOLOGIA AVANÇA QUANDO FALTA A AVALIAÇÃO DOS EFEITOS DOS PRODUTOS?}

A toxicologia, assim como a química, avança através de investigação e experimentação. Apesar deste fato, nem sempre se conhece a plena toxicidade de determinado produto de imediato. Infelizmente este avanço se dá geralmente através dos problemas que vão surgindo ao longo do tempo, à medida que novos produtos são inseridos no mercado consumidor. No Brasil, em 1946, estabeleceu-se uma primeira tentativa séria de regulamentar a produção de medicamentos, incluindo propaganda, controle de qualidade, fiscalização etc. por meio do decreto $20.397^{38}$. Mesmo com todo o aparato que se dispõe atualmente, erros sempre existirão. Tem-se como exemplo o remédio Vioxx ${ }^{45}$ que, mesmo após os testes rigorosos necessários para sua aprovação pelas agências fiscalizadoras ("Federal Drug Agency" - FDA, Agência Nacional de Vigilância Sanitária - ANVISA, etc), causou problemas a inúmeras pessoas no mundo inteiro, havendo um aumento na taxa de ataques cardíacos e problemas de coração nos seus usuários.

O grande problema com relação a casos como este é que, diferentemente do início do século XX, a velocidade com que um medicamento ou produto novo é difundido em nível mundial é muito maior, gerando sempre uma disputa entre o lado científico e o lado financeiro dos fabricantes de produtos farmacêuticos e químicos, que buscam o lucro. A pesquisa acaba fornecendo resultados rápidos, e muitas vezes duvidosos, devido a esta pressão. Conforme citado anteriormente, pouco se conhece da toxicologia do que é vendido atualmente, fato este devido ao alto custo desse estudo, do tempo relativamente longo, das muitas cobaias necessárias para realização de testes e bastante burocracia legal ${ }^{46}$.

\section{A SUBSTITUIÇÃO DOS PRODUTOS POR OUTROS}

A substituição de produtos danosos por outros menos agressivos, não importando sua aplicação, é motivada pela busca de um equilíbrio entre saúde, meio ambiente e eficácia do produto; hoje esta é a tendência mundial. Como exemplo dessa necessidade, podese acompanhar os problemas na saúde humana notificados no Brasil em 2001 devidos a produtos químicos (Tabela 7) ${ }^{47}$.

No caso da área farmacêutica, cabe destacar a resolução n ${ }^{\circ} 528$ da ANVISA ${ }^{48}$, que é um exemplo interessante de substituição de produtos consagrados pelo uso popular, por décadas, por outros mais seguros. Trata-se da proibição da comercialização e da fabricação
Tabela 7. Dados de intoxicação química notificados no Brasil (2001) ${ }^{47}$

\begin{tabular}{lcc}
\hline Produtos & Casos de intoxicação Mortes \\
\hline Agrotóxico de uso agrícola & 2690 & 91 \\
Agrotóxico de uso doméstico & 1583 & 2 \\
Raticidas & 2744 & 31 \\
Domissanitários (produtos de limpeza) & 4131 & 6 \\
Produtos químicos industriais & 2635 & 8 \\
Metais & 219 & $\mathrm{sr}^{*}$ \\
\hline
\end{tabular}

$*$ sr $=$ sem registro

em território nacional do mercúrio-cromo (2,7-dibromo-4hidroximercurifluoresceína) e do merthiolate (timerosal: $\mathrm{C}_{9} \mathrm{H}_{9} \mathrm{HgO}_{2} \mathrm{SNa}-\mathrm{DL}_{50}$ em ratos (via oral) ${ }^{18}: 75 \mathrm{mg} \mathrm{kg}^{-1}$ ), ambos contendo mercúrio na fórmula química do princípio ativo, pelas seguintes justificativas:

\footnotetext{
"considerando que os medicamentos à base de derivados mercuriais, possuem relação risco e benefício desfavorável quando comparados com outros antissépticos tópicos; considerando as diretrizes internacionais que recomendam a redução da exposição aos mercuriais, resolve: Art. $1^{\circ}$ Proibir o uso de compostos mercuriais nos medicamentos".
}

No campo dos agrotóxicos a tendência está cada vez mais centrada no uso de novos produtos que apresentem menor toxicidade ao meio ambiente e ao homem do campo. Quanto aos pesticidas, o grande foco da pesquisa está em torná-los cada vez mais específicos utilizando venenos de plantas como base para a síntese de novos produtos (ex.: piretróides e piretrinas) e, também, nos chamados pesticidas biorracionais, que consistem em utilizar vírus, bactérias e outros agentes naturais de controle de pragas (predadores) ${ }^{42}$.

$\mathrm{Na}$ área alimentar, a cada problema detectado por um aditivo químico, logo se retira este do mercado substituindo-o por um outro, menos agressivo.

\section{CRITÉRIOS PARA APROVAÇÃO DO USO DE UM PRODUTO}

\section{Área farmacêutica}

A partir do incidente com a talidomida aumentou a exigência por parte das autoridades com relação à liberação de um novo medicamento no mercado. Atualmente, o fabricante deve realizar ensaios com cobaias em laboratório para avaliação de efeitos toxicológicos, farmacocinéticos e farmacodinâmicos. Somente depois desta etapa parte-se para ensaios em organismos humanos ${ }^{49}$. Estes ensaios são divididos em três fases: Fase 1 - são realizados ensaios com o medicamento em dezenas de voluntários saudáveis. Nesta fase há um primeiro contato farmacológico da substância ativa em humanos, sendo avaliadas também segurança e dosagem; Fase 2 - avalia-se a eficácia do medicamento em doentes, primeiramente em ensaios piloto e, posteriormente, a utilização ocorre em doentes selecionados, coletando também os dados da segurança do medicamento e, Fase 3 - aumenta-se tanto a amostragem como diversifica-se a gama de pessoas nos testes. Nesta fase, também, são incluídos tratamentos mais prolongados com o produto, cerca de 6 a 12 meses, visando a flexibilidade na dosagem, assim como coletar dados de segurança e eficácia do mesmo.

Estas três fases, assim como os ensaios iniciais, são realizadas pelo fabricante do medicamento, ficando uma $4^{\mathrm{a}}$. fase, conhecida também como farmacovigilância, sob responsabilidade do órgão regulamentador do Ministério da Saúde. A farmacovigilância surgiu 
da necessidade do governo poder acompanhar a segurança de um medicamento desde seu surgimento. Sua definição pela Organização Mundial da Saúde (OMS), segundo a norma 425 de 1966, é:

\begin{abstract}
"Farmacovigilância é o conjunto de procedimentos de detecção, registro, e avaliação das reações adversas para determinação de sua incidência, gravidade e relação de causalidade com a forma de dosificação de um medicamento com fórmula magistral, com o objetivo último da prevenção, com base no estudo sistemático e pluridisciplinar das ações dos medicamentos."
\end{abstract}

No Brasil este papel fica a cargo da ANVISA, que se utiliza da Resolução RDC n 136, de 29/5/2003, para o registro de um medicamento novo.

\section{Área agrícola e meio ambiente}

Pode-se definir agrotóxicos e outros produtos com esta finalidade, conforme descrito no artigo $1^{\circ}$ do decreto $\mathrm{n}^{\circ} 4074$ do Ministério da Agricultura, Pecuária e Abastecimento, de 4/1/2002 como: "Produtos e agentes de processos físicos, químicos ou biológicos, destinados ao uso nos setores de produção, no armazenamento e beneficiamento de produtos agrícolas, nas pastagens, na proteção de florestas, nativas ou plantadas, e de outros ecossistemas e de ambientes urbanos, hídricos e industriais, cuja finalidade seja alterar a composição da flora ou da fauna, a fim de preservá-las da ação danosa de seres vivos considerados nocivos, bem como as substâncias e produtos empregados como desfolhantes, dessecantes, estimuladores e inibidores de crescimento".

Ainda neste decreto, artigo $2^{\circ}$, "estipula o Ministério da Agricultura, Pecuária e Abastecimento, Saúde e do Meio Ambiente estabelecer o limite máximo de resíduos e o intervalo de segurança dos agrotóxicos e afins", além de "estabelecer os parâmetros para rótulos e bulas de agrotóxicos e afins".

Os critérios para que um produto possa ser utilizado no meio ambiente dependem de alguns parâmetros. Pelo decreto citado, conforme capítulo 3 seção 1 do artigo $12^{\circ}$, estipula que para o registro: "Os produtos de baixa toxicidade e periculosidade terão a tramitação de seus processos priorizada, desde que aprovado pelos órgãos federais competentes o pedido de prioridade, devidamente justificado, feito pelos requerentes do registro".

$\mathrm{O}$ artigo $20^{\circ}$ define "o registro de novo produto agrotóxico, seus componentes e afins somente será concedido se a sua ação tóxica sobre o ser humano e o meio ambiente for, comprovadamente, igual ou menor do que a daqueles já registrados para o mesmo fim".

Ainda merece destaque que existe uma resolução do Conselho Nacional do Meio Ambiente (CONAMA), n 334, de 3/4/2003, que disciplina a devolução de embalagens vazias de agrotóxicos para pontos de coleta a fim de que seja dada a destinação final adequada, conforme descrito nos artigos 51 a 60 do decreto 4074 .

\footnotetext{
Alimentos

Serão destacados apenas os aditivos, visto sua importância e diversidade.

Assim como os produtos utilizados no meio ambiente e na área farmacêutica, os aditivos alimentares e seus metabólitos também precisam ser analisados com relação à sua toxicidade. Basicamente inicia-se este estudo através da utilização de cobaias, tais como ratos, cães e coelhos, a fim de se obter dados dos efeitos tóxicos do produto a curto e longo prazo. Estes testes monitoram o comportamento dos animais, seu crescimento, taxa de mortalidade, reprodução, química do sangue e desenvolvimento de tumores, durante um período
}

de 90 dias. Assim como existe o $\mathrm{DL}_{50}$, usado de modo geral na toxicologia, na área alimentar define-se a menor quantidade de um aditivo que não produz nenhum efeito tóxico ao ser humano. Esse parâmetro é chamado de NOEL ("No-effect level"). Este valor é, geralmente, dividido por 100 a fim de se obter um valor máximo e seguro ao consumo humano, que é denominado ADI ("acceptable daily intake") $)^{50}$. Foi montado um sistema a fim de padronizar a qualidade dos alimentos, o chamado sistema CODEX Alimentarius, baseado nas diretrizes e recomendações da FAO/OMS (Organização para Alimentação e Agricultura/Organização Mundial da Saúde) que influenciam todo o sistema legislativo alimentício mundial ${ }^{46}$. No Brasil, o órgão responsável pela fiscalização neste setor é a ANVISA.

\section{MELHORIA NA QUALIDADE DE UM PRODUTO}

É comum verificar que um determinado produto comercial se revela eficaz. Contudo, ao lado dessa eficácia, podem aparecer alguns efeitos indesejáveis, conhecidos como efeitos colaterais. Além dos efeitos devido ao uso prolongado ou às próprias características intrínsecas, há uma terceira categoria de efeito colateral devido à pureza do produto em questão, isto é, o controle de impurezas presentes no mesmo. Dois exemplos típicos são apresentados a seguir, e demonstram que, afora substituir um produto por outro, o controle de qualidade pode ser decisivo para manter esse produto no mercado, conquistando o reconhecimento do público consumidor.

\section{Água oxigenada}

Um dos problemas referentes a esse produto de amplo emprego doméstico e industrial é a sua durabilidade, visto que se decompõe com o tempo

$\mathrm{H}_{2} \mathrm{O}_{2} \rightleftharpoons \mathrm{H}_{2} \mathrm{O}+1 / 2 \mathrm{O}_{2}$

Ácidos, metais e rugosidades do recipiente, além de luz e calor, favorecem a decomposição.

No final da década de 1920, uma empresa farmacêutica publicou um cartaz afirmando que sua água oxigenada era isenta de ácidos minerais e outras impurezas que aceleravam o processo de decomposição e também tinha efeitos adversos a seus usuários (tais como, alergia ou branqueamento insatisfatório de tecido e papel). Isso se compreende quando se tem em mente a rota de síntese do $\mathrm{H}_{2} \mathrm{O}_{2}$ até então empregada:

$$
\begin{aligned}
& \mathrm{BaCO}_{3}(\mathrm{~s})+2 \mathrm{HCl}(\mathrm{aq}) \rightleftharpoons \mathrm{BaCl}_{2}(\mathrm{aq})+\mathrm{CO}_{2}(\mathrm{~g})+\mathrm{H}_{2} \mathrm{O}(\mathrm{l}) \\
& \mathrm{BaCl}_{2}(\mathrm{aq})+2 \mathrm{NaOH}(\mathrm{aq}) \rightleftharpoons \mathrm{Ba}(\mathrm{OH})_{2}(\mathrm{~s})+2 \mathrm{NaCl}(\mathrm{aq}) \\
& \mathrm{Ba}(\mathrm{OH})_{2}(\mathrm{~s}) \longrightarrow \mathrm{BaO}(\mathrm{s})+\mathrm{H}_{2} \mathrm{O}(\mathrm{v})
\end{aligned}
$$

$\mathrm{BaO}(\mathrm{s})+1 / 2 \mathrm{O}_{2}(\mathrm{~g}) \underset{500{ }^{\circ} \mathrm{C}}{\longrightarrow} \mathrm{BaO}_{2}(\mathrm{~s})$

$\mathrm{BaO}_{2}(\mathrm{~s})+\mathrm{H}_{2} \mathrm{SO}_{4}(\mathrm{aq}) \rightleftharpoons \mathrm{BaSO}_{4}(\mathrm{~s})+\mathrm{H}_{2} \mathrm{O}_{2}(\mathrm{aq})$

As dificuldades que comprometiam a qualidade da água oxigenada provinham do ácido sulfúrico empregado na reação (6), que era obtido pelo processo das câmaras de chumbo, segundo as reações simplificadas:

$$
\begin{aligned}
& \mathrm{NO}(\mathrm{g})+1 / 2 \mathrm{O}_{2}(\mathrm{~g}) \rightleftharpoons \mathrm{NO}_{2}(\mathrm{~g}) \\
& \mathrm{SO}_{2}(\mathrm{~g})+\mathrm{H}_{2} \mathrm{O}(\mathrm{l}) \rightleftharpoons \mathrm{H}_{2} \mathrm{SO}_{3}(\mathrm{aq})
\end{aligned}
$$


$\mathrm{H}_{2} \mathrm{SO}_{3}(\mathrm{aq})+\mathrm{NO}_{2}(\mathrm{~g}) \rightleftharpoons \mathrm{H}_{2} \mathrm{SO}_{4}(\mathrm{aq})+\mathrm{NO}(\mathrm{g})$

As impurezas encontradas no ácido eram selênio, arsênio, chumbo, ferro, cobre, zinco, mercúrio, antimônio e telúrio, que tanto aceleram a decomposição da água oxigenada quanto conferem à solução propriedades indesejáveis, como toxicidade devido aos metais, cor, odor, etc. Hoje isso não ocorre mais face à obtenção do $\mathrm{H}_{2} \mathrm{SO}_{4}$ pelo processo (catalítico) de contato:

$\mathrm{SO}_{2}+1 / 2 \mathrm{O}_{2} \underset{\Delta}{\stackrel{\mathrm{V}_{2} \mathrm{O}_{5}}{\longrightarrow}} \mathrm{SO}_{3}$

$\mathrm{H}_{2} \mathrm{SO}_{4}+\mathrm{SO}_{3} \rightleftharpoons \mathrm{H}_{2} \mathrm{~S}_{2} \mathrm{O}_{7}$

$\mathrm{H}_{2} \mathrm{~S}_{2} \mathrm{O}_{7}+\mathrm{H}_{2} \mathrm{O} \rightleftharpoons 2 \mathrm{H}_{2} \mathrm{SO}_{4}$

A situação também mudou quando se modificou o processo de obtenção da água oxigenada:

$2 \mathrm{SO}_{4}^{2-}(\mathrm{aq}) \underset{\text { eletrolítica }}{\stackrel{\text { oxidação }}{\longrightarrow}} \mathrm{S}_{2} \mathrm{O}_{8}^{2-}(\mathrm{aq})+2 \mathrm{e}^{-}$

$2 \mathrm{e}^{-}+2 \mathrm{H}^{+}(\mathrm{aq}) \longrightarrow \mathrm{H}_{2}(\mathrm{~g})$

A solução de partida pode ser ácido sulfúrico ou seu sal de amônio. Na seqüência o íon peroxidissulfato é hidrolisado:

$\mathrm{S}_{2} \mathrm{O}_{8}{ }^{2-}(\mathrm{aq})+2 \mathrm{H}_{2} \mathrm{O}(\mathrm{l}) \rightleftharpoons 2 \mathrm{SO}_{4}^{2-}(\mathrm{aq})+\mathrm{H}_{2} \mathrm{O}_{2}(\mathrm{aq})+2 \mathrm{H}^{+}(\mathrm{aq})$

(15)

e o $\mathrm{H}_{2} \mathrm{O}_{2}$ é removido do meio por destilação a vácuo, livrando-o de suas impurezas ácidas e metálicas e permitindo obter materiais com alta concentração do produto $^{51}$. O resíduo do processo volta ao ciclo do produto. Além disso, a adição de substâncias estabilizantes (como o pirofosfato de sódio, $\mathrm{Na}_{4} \mathrm{P}_{2} \mathrm{O}_{7}$ ) e o emprego de frascos plásticos (em lugar do vidro) permitiram prolongar a vida útil das soluções de $\mathrm{H}_{2} \mathrm{O}_{2}$.

\section{Água sanitária}

A água sanitária, de amplo uso como alvejante industrial e desinfetante doméstico, nada mais é do que uma solução alcalina $(\mathrm{NaOH})$ de hipoclorito de sódio $(\mathrm{NaClO})$, que contém também $\mathrm{NaCl}$, obtida segundo a reação 16 :

$\mathrm{Cl}_{2}(\mathrm{~g})+2 \mathrm{NaOH}(\mathrm{aq}) \rightleftharpoons \mathrm{NaClO}(\mathrm{aq})+\mathrm{NaCl}(\mathrm{aq})+\mathrm{H}_{2} \mathrm{O}(\mathrm{l})(16)$

O excesso de base favorece o deslocamento do equilíbrio para a direita. A dificuldade refere-se à pureza do $\mathrm{NaOH}$ (teor de carbonatos, metais e matéria orgânica presente). Essas impurezas, além da luz, levam à decomposição do $\mathrm{NaClO}$ por desproporcionamento (reação 17) e por redução total do íon $\mathrm{OCl}^{-}$a $\mathrm{Cl}^{-}$:

$3 \mathrm{NaClO}(\mathrm{aq}) \rightleftharpoons \mathrm{NaClO}_{3}(\mathrm{aq})+2 \mathrm{NaCl}(\mathrm{aq})$

A quantidade do íon hipoclorito em solução aquosa é limitada pela baixa solubilidade do $\mathrm{Cl}_{2}$ em água pura $\left(0,06 \mathrm{~mol} \mathrm{~L}^{-1}\right.$ a $\left.25^{\circ} \mathrm{C}\right)$. $\mathrm{O}$ uso de base aumenta a concentração do referido íon, mas a pureza do álcali tem efeito crítico sobre a estabilidade da solução. Dois processos permitiram melhorar as características das soluções de $\mathrm{NaClO}$ :

(a) eletrólise de cloretos alcalinos com células que impeçam o contato do $\mathrm{Cl}_{2}$ (anodo) com o hidróxido (catodo);

(b) reação de cloro com suspensão aquosa de $\mathrm{HgO}$ :

$\mathrm{Cl}_{2}(\mathrm{~g})+\mathrm{HgO}(\mathrm{s})+\mathrm{H}_{2} \mathrm{O}(\mathrm{l}) \rightleftharpoons \mathrm{HgCl}_{2}(\mathrm{aq})+2 \mathrm{HClO}(\mathrm{aq})$
$\mathrm{O} \mathrm{HgCl}_{2}$, não dissociado, favorece o deslocamento do equilíbrio para a direita. A rota (b) só é utilizada em escala laboratorial, dada a periculosidade do $\mathrm{Hg}^{2+}$. A alternativa é a obtenção do $\mathrm{NaOH}$ segundo:

$\mathrm{Na}_{2} \mathrm{CO}_{3}(\mathrm{aq})+\mathrm{Ca}(\mathrm{OH})_{2}(\mathrm{~s}) \rightleftharpoons \mathrm{CaCO}_{3}(\mathrm{~s})+2 \mathrm{NaOH}(\mathrm{aq})$

onde as impurezas são arrastadas junto com o precipitado, melhorando a pureza do $\mathrm{NaOH}^{51}$.

\section{CONCLUSÕES}

Quando a tecnologia avança percebe-se que o que parecia seguro e bem estabelecido no passado pode revelar-se inadequado e mesmo nocivo à saúde e ao meio ambiente em geral, fruto do desconhecimento das propriedades dos produtos que o nível de conhecimento de então não podia proporcionar. Assim, com o acúmulo de erros e tragédias notou-se a necessidade de adotar práticas bem mais cautelosas quando da liberação de um novo produto no mercado, onde a química tem um papel fundamental.

Qualidade é muito mais que cumprir a finalidade à qual o produto se destina. Segurança e esclarecimento frente aos consumidores são itens componentes de uma visão abrangente e responsável dessa qualidade, hoje reconhecida como um fator indispensável no contexto mercadológico, tal como observado nos programas de "atuação responsável" adotados pela indústria química. O primeiro passo para um uso seguro de produtos químicos é saber identificá-los quanto aos perigos para a saúde, o meio ambiente, e os meios para seu controle.

A tendência futura é a redução dos erros e das lamentações provenientes do uso de produtos químicos, conquanto os princípios da ética profissional e o correto emprego pelos consumidores sejam verificados. A satisfação hoje conseguida por um produto em uma dada aplicação não impossibilita a busca de novas propostas que ampliem ainda mais esse quadro de eficiência, seja pela troca do produto por outro ainda mais eficiente, como também pela melhoria da rota de síntese eliminando, assim, impurezas que comprometem a qualidade. O progresso na área de toxicologia permite um aumento da segurança dos produtos químicos nas diversas possibilidades de seus usos pois sabese que hoje seria impensável e improvável que a vida humana, sem a utilização dos produtos químicos, chegasse ao patamar atual em todos os campos, sejam eles de ciência como a do bem-estar. Ao mesmo tempo há um revés nesta história: assim como já era no passado, a química deve ser encarada como uma ciência e não apenas a solução para todos os problemas; acima de tudo, ela é uma ferramenta da qual pode-se utilizar, consciente e responsavelmente, a fim de obter o máximo proveito daquilo que ela pode oferecer à humanidade.

É muito importante focar o aspecto da segurança dos produtos químicos, muitos encontrados nas residências, aos cidadãos comuns que não estão habituados a uma ligação entre o conhecimento químico e o seu dia-a-dia. Levar este tipo de informação à população agrega valores à cidadania e mostra responsabilidade com relação à saúde das pessoas e do planeta em que vivemos.

\section{REFERÊNCIAS}

1. Leicester, H. M.; The Historical Background of Chemistry, Dover Publications Inc.: Nova Iorque, 1971, p. 1-5.

2. Antunes, A. M. S.; Tese de Doutorado, Universidade Federal do Rio de Janeiro, Brasil, 1987.

3. Chassot, A.; A Ciência Através dos Tempos, Ed. Moderna: São Paulo, 1994.

4. www.pulverizador.com.br, acessada em Setembro 2004.

5. Manahan, S. E.; Toxicological Chemistry, $4^{\text {th }}$ ed., Lewis Publishers: Michigan, 1991

6. Kearney E. T.; Collect. Forum 2001, 16, 44. 
7. Goes R. C.; Toxicologia Industrial: Um Guia Prático para Prevenção e Primeiros Socorros, Ed. Revinter: Rio de Janeiro, 1997, p. 1-8.

8. w w w. cetes b.s p.gov.br/e mergencia/as pectos/ aspectos_toxicologia_conceitos.asp, acessada em Novembro 2004.

9. Loomis, T. A.; Essentials of Toxicology, Lea and Faebiger: Philadelphia, 1978, p. 67-69.

10. Swanson, M. B.; Davis, G. A.; Kincaid, L. E.; Environ. Toxicol. Chem. 1997, 16, 372.

11. Encyclopaedia of Occupational Health and Safety, The International Labour Office (Organização Internacional do Trabalho): Genebra, 1983.

12. Afonso, J. C.; Aguiar, R. M.; Quim. Nova 2004, 27, 837.

13. Stephen, W. I.; Townshend, A.; Chemistry in Britain 1984, 20, 1008.

14. Hamilton, A.; Johnstone, R.; Industrial Toxicology, Oxford University Press: Nova Iorque, 1945.

15. Calvet, E.; Química General Aplicada a la Industria con Práticas de Laboratório, Salvat Editores: Barcelona, 1936, vol. I.

16. www.jtbaker.com/msds/englishhtml/, acessada em Dezembro 2004.

17. Molinari, E.; Chimie Générale, Chimie Inorganique et Industrielle, $4^{\mathrm{a}}$ ed., Dunod: Paris, 1921, vol. 3.

18. ChemDAT, The Merck Chemical Database, Merck KGaA: Darmstadt, 2005.

19. Basin, J.; Lições de Chimica para o Uso dos Aspirantes a Todas as Escolas Superiores, Livraria Francisco Alves \& Cia: Rio de Janeiro, 1915.

20. The Index Merck, $12^{\mathrm{a}}$ ed., Merck \& Co. Inc.: Darmstadt, 1996.

21. Ostwald, W.; Éléments de Chimie Inorganique, $10^{\mathrm{a}}$ ed.; Gauthier-Villars: Paris, 1913, vol. II

22. Lyman, C. N.; General Chemistry Principles and Applications, D. C Heath \& Co. Publishers: Londres, 1914

23. The Index Merck; $13^{\mathrm{a}}$ ed., Merck \& Co. Inc.: Darmstadt, 2001.

24. Erdmann, H.; Traité de Chimie Minérale, $5^{\mathrm{a}}$ ed., Libraire Scientifique A Hermnann et Fils: Paris, 1933, cap. 2.

25. The Index Merck; 5 $5^{\mathrm{a}}$ ed., Merck: Darmstadt, 1940; $4^{\mathrm{a}}$ ed., Merck: Darmstadt, 1930.

26. Weast, R.; Handbook of Chemistry and Physics, 63 a ed., The CRC Press: Boca Raton, 1982.

27. Clayton Environmental Consultants; Medical Management of Chemical Exposure in the Petroleum Industry, American Petroleum Institute: Washington, 1982.

28. Oppenheimer, C.; Compendio de Química Inorgânica, $11^{\mathrm{a}}$ ed., Casa Editorial P. Salvat: Barcelona, 1923.

29. Gigon, A.; Nota terapêutica do medicamento "Tribromure de A. Gigon", Laboratórios Enila: Rio de Janeiro, 1941.
30. Teixeira, M. J.; Noções de Chimica Inorgânica, $14^{\mathrm{a}}$ ed., Livraria Francisco Alves Paulo de Azevedo e Cia.: Rio de Janeiro, 1930.

31. Smith, A.; Kendall, J.; General Chemistry a Cultural Course Based Upon the Texts of the Late, D. Appleton-Century Company: Nova Iorque, 1936.

32. D'Amato, C.; Torres, J. P. M.; Malm, O.; Quim. Nova 2002, 25, 995.

33. Gosselin, R. E.; Smith, R. P.; Hodge, H. C.; Clinical Toxicology of Commercial Products, $5^{\text {th }}$ ed., Williams and Wilkins: Baltimore, 1984, p. III123-III130.

34. Clarcke, B. L.; Marvels of Modern Chemistry, $2^{\text {nd }}$ ed., Harper \& Brothers: Nova Iorque, 1932.

35. Miracles of Invention and Discovery, Odhams Press: Londres, 1945.

36. Haynes,W.; Os Milagres da Química, Ed. do Globo: Porto Alegre, 1945.

37. Pinto, P. A.; Noções de Chimica Geral, Francisco Alves e Cia: Rio de Janeiro, 1908

38. Gorberg, S.; A Propaganda no Brasil Através do Cartão-postal 1900-1950, S. Gorberg: Rio de Janeiro, 2002.

39. Tambini, M.; O Design do Século, $2^{\mathrm{a}}$ ed., Ática: São Paulo, 2002

40. Stein, N.; Reclames da Bayer 1911-1942, Bayer do Brasil S. A.: São Paulo, 1986.

41. Oliveira, M. A.; Bermudez, J. A. Z.; Souza, A. C. M.; Cad. Saúde Pública 1999, 15, 99; Lima, L.M.; Fraga, C. A. M.; Barreiro, E. J.; Quim. Nova 2001, 24, 683 .

42. Delaplane, K. S.; Pesticide Usage in the United States: History, Benefits, Risks, and Trends, Cooperative Extension Service/The University of Georgia College of Agricultural and Environmental, Bulletin 1121, 2000.

43. Faria, M. V. C.; Noce, E. F. M.; Resíduos de Agrotóxicos Organofosforados e Carbamatos em Hortaliças e Frutas Consumidas no Rio de Janeiro, 2002.

44. The Time Magazine, $\mathrm{n}^{\circ} 63$, junho de 1947, p. 34

45. Jornal O Globo; Rio de Janeiro, 2 de outubro de 2004, caderno Ciência e Vida, p. 37.

46. www.setor1.com.br/aditivos/ava_toxi.htm, acessada em Novembro 2004

47. Dados de Intoxicação Química no Brasil em 2001, Jornal O Globo; Rio de Janeiro, 9 de novembro de 2003, caderno O País, p. 12.

48. Agência Nacional de Vigilância Sanitária; Resolução RE n ${ }^{\circ}$ 528, de 17 de abril de 2001, Diário Oficial da União, 18/04/2001.

49. Castro, L. L. C.; Fundamentos de Farmacoepidemiologia, GRUPURAM: Campo Grande, 2001.

50. www.quark.qmc.ufsc.br/qmcweb/artigos/aditivos.html, acessada em Outubro 2004

51. Ohlweiler, O. A.; Química Inorgânica, Ed. Edgard Blücher e Ed. da Universidade de São Paulo: São Paulo, 1972 